


\title{
The Manual Industries of Peru: indigenismo, trabajo manual y tutelaje artístico entre Lima y el Museo de Arte Moderno de Nueva York (1942-1948)
}

Horacio Ramos

The Graduate Center, CUNY hramos@gradcenter.cuny.edu Nueva York-Estados Unidos

\begin{abstract}
Resumen
En la década de los cuarenta y con el auspicio del Museo de Arte Moderno de Nueva York (MoMA), el artista estadounidense Truman Bailey dirigió una escuela-taller en Lima, en la que empleó y entrenó a cerca de 80 trabajadores, para producir artículos de lujo inspirados en artes populares andinas. En este ensayo sostengo que el taller constituyó no solo un proyecto indigenista de preservación de tradiciones indígenas, como afirmaron sus organizadores, Bailey y el influyente curador René d'Harnoncourt. Considero que el taller fue, además, y sobre todo, un espacio para la formación de trabajadores a partir del entrenamiento en diseño modernista y en modos de producción y comercialización del capitalismo industrial estadounidense.
\end{abstract}

Palabras clave: arte latinoamericano, indigenismo, modernismo, René d'Harnoncourt, Truman Bailey, arte popular, artes aplicadas

\begin{abstract}
In the forties and with the sponsorship of the Museum of Modern Art of New York (MoMA), the U.S artist Truman Bailey directed a school-workshop in Lima where he employed and trained nearly 80 workers to produce luxury items inspired by Andean popular arts. In this essay, the author argues that the workshop was not only an indigenous project to preserve indigenista traditions as its organizers, Bailey and influential curator René d'Harnoncourt, claimed. The author considers that the workshop was also and above all, a space for workers' formation through training in modernist design and modes of production and commercialization of U.S industrial capitalism.
\end{abstract}

Keywords: Latin American art, indigenismo, modernism, René d'Harnoncourt, Truman Bailey, arte popular, applied arts

Barsabas Cisneros, joven nacido en 1924 en Illimo, Chiclayo, sostiene una figura de madera con la mano izquierda mientras talla con la derecha los detalles finales de su obra (Fig. 1). A la derecha de Cisneros vemos una abigarrada mesa con objetos tallados en madera que evocan (a la vez que alteran la materialidad de) los toros de Pucará, un tipo de cerámica puneña que el influyente artista peruano José Sabogal volvería ícono de las artes populares durante esos

1 Una versión de este ensayo fue presentada en el simposio "Art History across the Americas: Key Terms, Debates, and Places of Knowledge”, organizado por María Isabel Baldasarre y Fernanda Pitta en el Clark Art Institute, los días 5 y 6 de abril del 2019. Desde entonces, se ha enriquecido con sugerencias de Gabriela Germaná, Natalia Majluf, Edward J. Sullivan, María Eugenia Yllia, Bruno Pinheiro y Mia R. Curran. Agradezco la invaluable información ofrecida por John Alfredo Davis Benavides y Katherine Román. 
años (Sabogal, 1949). ${ }^{2}$ El chiclayano, quien por el resto de su vida se identificó como "maestro artesano", se encuentra aquí produciendo toros de origen ayacuchano en el taller que el artista estadounidense Truman Bailey dirigió en el distrito de clase alta de Miraflores, Lima. ${ }^{3}$ Capturada por el prolífico fotógrafo estadounidense William Vandivert (quien fundó la agencia Magnum Photo en 1947), la fotografía destaca la habilidad manual de Cisneros, al ponerlo en primer plano, dándole primacía por sobre sus industriosos colegas, operando maquinarias en el fondo.

Tiempo después, el Washington Daily News publicó un artículo de Robert Ruark (1948) titulado "Yanqui astuto enseña a los peruanos que sale a cuenta ser primitivo". El "yanqui" en cuestión era Bailey. Luego de viajar (entre 1942 y 1943) por 38 ciudades del Perú -como Cuzco, Chiclayo y Tingo María- estudiando diseños y métodos de producción manual, Bailey abrió en 1945, con la artista limeña Graciela "Grace” Vallejo, un taller donde empleó a cerca de 80 trabajadores para producir -siguiendo sus diseños e instrucciones-artículos de lujo, con el fin de venderlos en Lima y Nueva York. ${ }^{4}$ El taller fue parte del proyecto The Manual Industries of Peru (Las industrias manuales del Perú), dirigido por Bailey, pero coordinado a la distancia por René d'Harnoncourt, gestor cultural y diplomático austriaco-estadounidense, con auspicio de la Inter-American Development Comission (Comisión Interamericana de Desarrollo) y el Museo de Arte Moderno de Nueva York (MoMA). La iniciativa fue parte del ambicioso proyecto de d'Harnoncourt de preservar las "tradiciones indígenas de las dos Américas"; una referencia a Norte y Sudamérica que dejaba de lado Centroamérica y el Caribe. ${ }^{5}$ El plan de d'Harnoncourt era que el taller sirviese como eje de otros en Ecuador y Colombia, y que en última instancia forme parte de una red de industrias manuales que incluiría también a India y China. El taller de Lima, sin embargo, parece ser el único que cristalizó. El proyecto fue trasladado al Ministerio de Fomento en 1946, donde tuvo una corta y ardua existencia. La referencia más tardía que he encontrado sobre el taller, en 1951, sugiere que se había vuelto una iniciativa privada de Bailey (Windsor, 1951).

The Manual Industries enlaza y tensiona dos historias del arte latinoamericano que, a menudo, son contadas por separado. Por un lado, estudios sobre artes populares, como los de Karen Cordero (2010) o María Eugenia Yllia (2006), se han enfocado en las décadas de 1920 a 1940, para analizar cómo las prácticas manuales de artistas percibidos como indígenas se insertaron en espacios oficiales del arte, en el marco de las políticas culturales de países con ingentes poblaciones indígenas, como México y Perú. ${ }^{6}$ Por otro lado, estudios sobre arquitectura y diseño modernista, como los de M. C. Loschiavo dos Santos (1995), Ana Elena Mallet (2006) y Jorge Rivas (2015), se han enfocado en las décadas de 1940 a 1960, para destacar la ideología desarrollista que informó las industrias privadas y públicas de países como México, Brasil y Venezuela. ${ }^{7}$

2 Las figuras de cerámica conocidas como "toros de Pucará" fueron en realidad producidas en Checca Pupuja (Azángaro, Puno) y comercializadas luego en Pucará, Puno (Spahni, 1966, p. 55).

3 Rosa Elena Cisneros Ccollacondo, viuda de su nieto Mario Edgar Cisneros Véliz, lo recuerda como "maestro artesano" en un documento de mayo del 2018, compartido en la web FamilySearch, https://www.familysearch.org/tree/person/memories/LZK5-GVL

4 A menos que cite una carta o documento específico, las descripciones del taller de Bailey son tomadas de Bailey y Vallejo (1946).

5 "Memorandum on a proposed plan for the study and promotion of the native arts and crafts of the two Americas", ca. 1941. The Museum of Modern Art Archives, NY; Collecion RdH; Section II.28.

6 Excede a los alcances de este ensayo ofrecer un repaso exhaustivo por los numerosos estudios sobre arte popular peruano y mexicano de la primera mitad del siglo XX. Destaco a Cordero e Yllia, en tanto ambas han estudiado sistemáticamente la inserción de las llamadas "artes populares" en espacios oficiales de arte. Para un repaso historiográfico sobre el arte popular peruano, ver Germaná y Borea (2008).

7 Para un reciente estado de la cuestión sobre estudios de diseño modernista en Venezuela, Brasil y México, con sendos ensayos escritos por los autores mencionados arriba, ver Rangel (ed.) (2015). Para una visión panorámica sobre cómo instituciones norteamericanas auspiciaron y exhibieron arquitectura y diseño latinoamericano en el periodo, que además discute The Manual Industries of Peru, ver Del Real (2012). 
En este ensayo sostengo que The Manual Industries apuntó no solo a la preservación de tradiciones indígenas (como afirmaron sus promotores), sino también a la formación de trabajadores, a partir del entrenamiento en diseño modernista y en modos de producción y comercialización del capitalismo industrial estadounidense. ${ }^{8}$ Mi texto analiza la conexión entre discursos indigenistas y desarrollistas articulados en el taller, partiendo del análisis de textos oficiales, fotografías y objetos del proyecto, así como de la correspondencia entre d'Harnoncourt y Bailey. Dejo para futuras investigaciones examinar la vida social del taller, a partir de entrevistas a los familiares de sus trabajadores, como Barsabas Cisneros. ${ }^{9}$

Para evidenciar la influencia del desarrollismo e industrialismo estadounidenses en este proyecto de preservación, empezaré analizando textos y cartas de d'Harnoncourt y Bailey, las cuales situaré en el marco de las relaciones diplomáticas que dicho país estableció con Latinoamérica durante y tras de la Segunda Guerra Mundial. Luego, analizaré cómo los objetos del taller y las fotografías que Vallejo produjo para el MoMA promovieron una intersección entre tradiciones indígenas y los métodos del capitalismo industrial. Cabe notar que, si bien d'Harnoncourt tuvo un lugar prominente en proyectos desarrollistas en México y Estados Unidos, con comunidades rurales indígenas desde los años 20, su coordinación en Perú estuvo limitada por la distancia y la falta de apoyo institucional local. Así, pues, el proyecto no cristalizó en una escena de industrias manuales duradera. Mis reflexiones finales discuten las contradicciones en el discurso de empoderamiento del "maestro artesano" que promovía el taller.

Mi argumento parte de lo sugerido por investigadoras como Gabriela Germaná y Giuliana Borea (Germaná y Borea, 2008; Borea, 2017), quienes han notado cómo la distinción discursiva entre "arte" y "arte popular" -consolidada entre las décadas de 1930 y 1950 en Limageneró una división racializada entre circuitos, agentes y formatos artísticos; entre, por un lado, los formatos y espacios de artistas urbanos blanco-mestizos y, por otro, los de sus pares de origen rural e indígena. Este proceso se dio a la par de lo que el historiador Paulo Drinot (2011) ha llamado (inspirado en los trabajos de Marisol de la Cadena) un proyecto cultural de "desindianización" del trabajador peruano a partir del capitalismo industrial. Así, si en los años 40 la noción de "arte popular" fue asociada a comunidades indígenas, el trabajo industrial fue asociado al mestizo urbano. Al existir en la intersección entre las artes manuales y la industria, el taller del Bailey ofreció un espacio para que personas de clase trabajadora y de diversos orígenes raciales puedan afirmar simultáneamente una identidad de artesanos y de obreros. En última instancia, espero que enfocarme en este caso permita reconsiderar el rol invisibilizado que personas racializadas y de clase trabajadora tuvieron en las redes del arte moderno de las Américas.

\section{Artes indígenas y redes diplomáticas}

La tensión entre arte manuales y producción industrial se hace patente desde la portada del catálogo The Manual Industries of Peru, diseñado por Christian Miller y publicado por el MoMA en 1946 (Fig. 2). Ahí vemos en primer plano tres cerámicas de Quinua, Ayacucho, que representan probablemente un toro, un perro y una oveja. Grace Vallejo fotografió las tres figuras en línea, pero desde un ángulo diagonal, otorgándole un tono serial a su composición. Como la historiadora del arte Harper Montgomery (2014) ha notado para el contexto mexicano, la presentación grupal de "tipologías" de artes populares fue un lugar

8 Patricio Del Real (2012) y Olga Herrera (2017) ofrecen miradas panorámicas sobre el intervencionismo y la promoción de la cultura estadounidense en Sudamérica a través del arte.

9 He podido identificar en Lima a familiares de artistas como Barsabas Cisneros y Óscar San Miguel. Era mi intención entrevistar a tales familiares en la segunda parte del 2020, pero la suspensión de vuelos comerciales entre Perú y Estados Unidos (donde actualmente resido) debido la pandemia de COVID-19 imposibilitó dicha opción. 


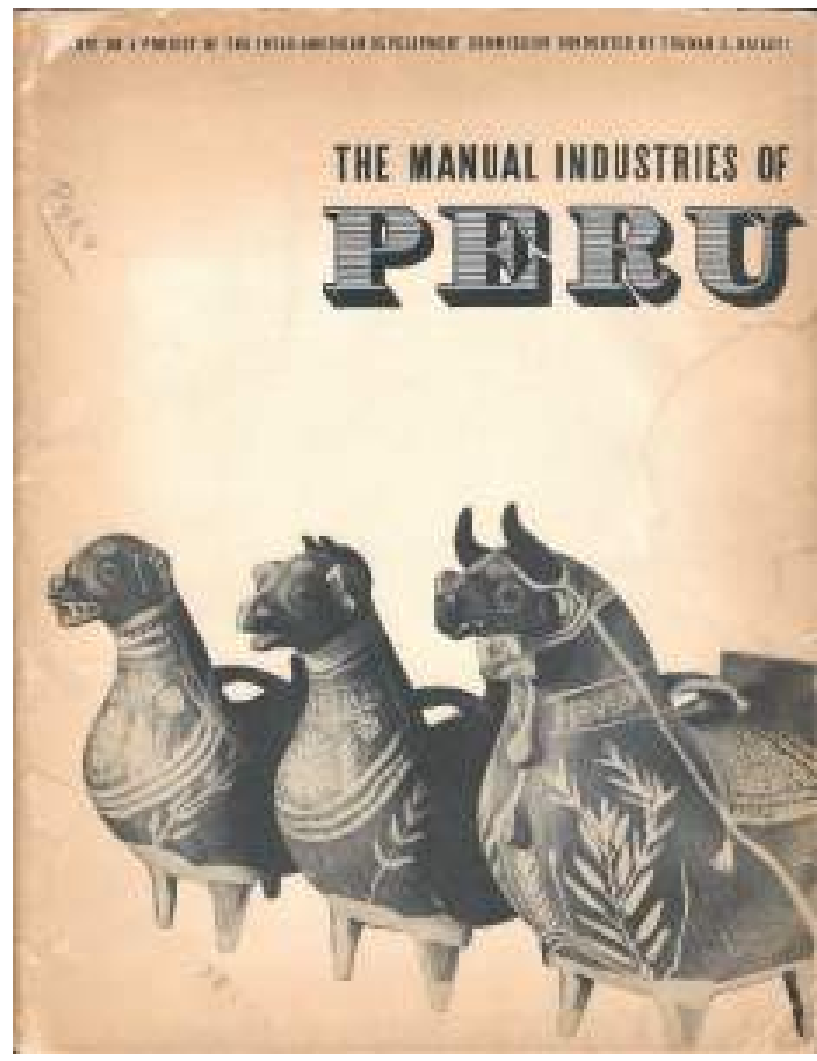

Fig. 2. Christian Miller (diseño) y Graciela "Grace" Vallejo (fotografía). Portada, 1946. Fuente: Bailey y Vallejo (1946) común en su representación fotográfica desde los 20. Si bien la fotografía de Vallejo alude a ese marco de referencia visual, el diseño de Miller utiliza un fondo vacío, que resuena con un tipo de publicidad comercial internacional que, desde la década de 1910 , ofertó mercancías "en línea de producción" sobre un fondo abstracto. ${ }^{10}$ En tensión con tal serialidad, cada objeto afirma su individualidad, al ostentar sendas decoraciones florales y textos.

También, claramente indicado en la portada, vemos el financiamiento del Comité Interamericano de Desarrollo, una institución estadounidense que desarrolló proyectos diplomáticos con países latinoamericanos durante y después de la Segunda Guerra Mundial. The Manual Industries fue el primer proyecto de René d'Harnoncourt como presidente del Comité de Industrias Manuales, una subsec-

ción del Comité Interamericano. ${ }^{11}$ Antes de asumir tal cargo, el austriaco trabajó como organizador de exhibiciones de arte popular en México. Ahí entró en contacto con los talleres que Gerardo Murillo, Dr. Atl (director del Comité de Artes Populares mexicano) organizó durante los años 20 con comunidades indígenas (López, 2010). El proyecto más ambicioso de d'Harnoncourt en este periodo fue Mexican Arts, una muestra itinerante que empezó su recorrido en el Ministerio de Educación de México y terminó en el Museo Metropolitano de Nueva York en 1931. D’Harnoncourt migró luego a Estados Unidos, donde curó para el MoMA exhibiciones como Indian Art in the United States (1941), Arts of the South Seas (1946) y Ancient Arts of the Andes (1954). ${ }^{12}$ Tales muestras dieron cuenta de su interés por prácticas indígenas de las Américas, pero, además, consolidaron su posición medular en el museo. En 1944, d’Harnoncourt fundó y dirigió el Departamento de Industrias Manuales, y desde 1949 hasta 1968 trabajó como director general del MoMA.

10 El modelo del "tipo" fue establecido por la Werkbund alemana en la primera década del siglo XX, y repetida luego por la Bauhaus y otros talleres y agencias de diseño europeos y estadounidenses desde entonces (Kogod, 2015).

11 Para un repaso de las exhibiciones y de René d'Harnoncourt en el MoMA, ver Elligott (2018). Para una mirada crítica que considera factores geopolíticos, ver Herrera (2017, pp. 168-206),

12 Remito al notable archivo web de exhibiciones del MoMA para las notas de prensa, catálogos, listas de obras y vistas de sala de estas exhibiciones. Ver: Indian Art in the United States, 1941 (https://www.moma. org/calendar/exhibitions/2998); Art of the South Seas, 1946 (https://www.moma.org/calendar/exhibitions/3188); Ancient Arts of the Andes, 1954 (https://www.moma.org/calendar/exhibitions/3317). 
La prolífica gestión curatorial de d'Harnoncourt en los Estados Unidos fue paralela a su labor política. En 1937, d'Harnoncourt fue nombrado gerente general del recientemente fundado Indian Arts and Crafts Board (Concejo de Artes y Artesanías Indias). Dicha institución financió y reguló estándares para la producción de artes manuales de comunidades como los Navajo, Pueblo y Hopi, con el fin de comercializarlas y apoyar sus deprimidas economías (Schuchardt, 2015). Si los proyectos de Dr. Atl -de ecos socialistas y auspiciados por el Gobierno en la estela de la Revolución Mexicana- apuntaron a preservar modos de producción comunitarios y rurales, d'Harnouncourt buscó en cambio la inserción de las artes manuales indígenas en mercados capitalistas y urbanos (Montgomery, 2014).

Para su labor en Estados Unidos y Perú, d'Harnoncourt contó con el apoyo de su amigo, el banquero y político Nelson A. Rockefeller, quien fue tanto mecenas del MoMA (de 1932 a 1979) como coordinador general del Comité Interamericano de Desarrollo (de 1940 a 1958). La correspondencia entre d'Harnoncourt y Rockefeller, alojada en los archivos del MoMA, da cuenta del continuo diálogo político e intelectual entre ambos, así como de la influyente red de agentes políticos y culturales que articularon durante la Segunda Guerra Mundial y la Guerra Fría. ${ }^{13}$ De Perú, d'Harnoncourt mantuvo contacto con el intelectual Luis E. Valcárcel (director del Ministerio de Educación entre 1945 y 1946), con el político Víctor Raúl Haya de la Torre (fundador de la Alianza Popular Revolucionaria Americana), y con artistas como el influyente José Sabogal y César Calvo de Araujo. ${ }^{14}$

En 1943, Sabogal dio en préstamo extendido una pintura al MoMA y, luego, en 1949, dedicó la pintura Alegoría andina a Bailey. ${ }^{15}$ La composición exhibe formas artísticas estimadas tanto por Bailey como por Sabogal: un toro de Pucará al centro, flanqueado por figuras de Quinua como las de la portada de The Manual Industries. En efecto, y en la estela de lo hecho antes por Alicia y Celia Bustamante en los treinta, Sabogal llevaba años promoviendo el estudio de artes populares andinas desde su cargo como director del Instituto de Arte Peruano, una sección del Museo de la Cultura Peruana. En 1946, Sabogal y otros artistas recorrieron ciudades y pueblos andinos para estudiar y coleccionar objetos, generando un periodo de intercambio entre, por un lado, artistas de origen indígena y rural andino, y por otro, artistas y clientelas limeños. ${ }^{16}$

Al abrir el catálogo The Manual Industries, vemos sendos textos de Luis Valcárcel, quien afirmó que el proyecto "inició el renacimiento de las artesanías (crafts) peruanas", y de Haya de la Torre, quien declaró que se trató de "la mejor contribución contemporánea al campo de la artesanía (craftmanship)". Tales encomios replicaban el ideario de d'Harnoncourt. En 1943, este envió una carta a Rockefeller explicando sus dos objetivos principales. ${ }^{17}$ Primero, ayudar a la población a desarrollar "pequeñas industrias que necesitan poco capital y equipo y que puedan utilizar las tradiciones existentes de comercio e industria locales". Segundo, "preservar las finas tradiciones artesanales que están en peligro de desaparecer". D’Harnoncourt tuvo la intención de que el taller de Lima opere como sede regional para

13 La biblioteca del MoMA resguarda los archivos de d'Harnoncourt, los cuales dan cuenta de la escala global de sus proyectos. Ver https://www.moma.org/research-and-learning/archives/finding-aids/dHarnoncourtf

14 Para la comunicación con Calvo de Araujo, ver "American Embassy, Lima, 3 de mayo de 1949”. The Museum of Modern Art Archives, NY; Collection RdH; Section Folder II.22.

15 La pintura Joven ayacuchana de Sabogal fue adquirida durante los viajes de Lincoln Kirstein -también curador del MoMA- por Sudamérica, y que la historiografía ha develado como parte de un plan mayor de Rockefeller para vigilar el avance de ideas socialistas en países latinoamericanos (Greet 2019, pp. 144-154). Sobre Alegoría andina, ver Villegas (2006) y Majluf y Wuffarden (2011, pp. 118-119).

16 Sobre la labor de Sabogal en el Instituto de Arte Peruano, ver Villegas (2006). Sobre los viajes y exhibiciones de arte popular organizados por las hermanas Bustamante en los treintas, ver Yllia y Carpio (2006).

17 “Memorandum René d'Harnoncourt a Nelson A. Rockefeller”, 30 de marzo de 1943. The Museum of Modern Art Archives, New York; Collection RdH; Section Folder II.29. 
otros talleres en Ecuador y Colombia. ${ }^{18}$ El énfasis panamericanista, en todo caso, no fue un elemento tangencial o retórico, sino que fue medular. En una carta de 1945, el último año de la Segunda Guerra Mundial, d'Harnoncourt afirmó que las artes indígenas de las Américas eran la única producción artística que no podía ser replicada por agencias "noamericanas". ${ }^{19}$ La Administración del presidente José Luis Bastamente y Rivero (1945-1948) implicó un acercamiento político con los Estados Unidos. Perú recibió apoyo de entidades gubernamentales estadounidenses, pero también de agencias privadas, como la Fundación Rockefeller (Contreras y Cueto, 2013).

El proyecto de d'Harnoncourt fue "panamericanista" también por la manera cómo replicó los métodos que este había usado antes en Estados Unidos. Además de cartas, D’Harnoncourt y Bailey intercambiaron fotografías para supervisar los "estándares" de sus productores peruanos. ${ }^{20}$ El tutelaje unilateral de Bailey y d'Harnoncourt se evidencia aún más al comparar The Manual Industries con las escuelas-talleres de tejido en paja que las artistas limeñas Elena y Victoria Izcue organizaron en los cuarentas, en ciudades del norte peruano como Chiclayo. ${ }^{21}$ Estos talleres fueron parte del Taller Nacional de Artes Gráficas Aplicadas, una entidad dirigida por ellas y financiada por la Dirección del Fomento y Obras Públicas del Perú. Cabe señalar que las hermanas Izcue optaron por nombrar profesoras de talleres a tejedoras locales como Genoveva Llontop o Francisca Ballena. Además, como han notado Natalia Majluf y Luis Eduardo Wuffarden (1999), los talleres no alteraron diseños locales para imitar patrones precolombinos -uno de los intereses de Elena Izcue en su obra individual-, sino que se enfocaron en la producción de carteras, sombreros e individuales con técnicas y diseños en vigencia entre las tejedoras.

En una carta de 1943 a d'Harnoncourt, Bailey describió los talleres de las hermanas Izcue. Bailey cuestionó el "gusto" (taste) de su producción. Criticó, además, que las Izcue orientasen los diseños de sus talleres "para los indios" (are inclined to design for the Indians). ${ }^{22} \mathrm{Tal}$ afirmación aludía no solo a un juicio del tipo estético, sino también a su convicción de que los métodos de producción vigentes en contextos rurales no darían abasto para los mercados de la capital. En efecto -y como discutiré en la sección siguiente-, el proyecto de Bailey apuntó a producir obreros capaces de suplir la demanda de mercados limeños e internacionales.

\section{Artistas y obreros}

A través de los textos de d'Harnoncourt y Bailey, y de las fotografías de Grace Vallejo, el catálogo The Manual Industries of Peru (Bailey y Vallejo, 1946) relata dos viajes. Primero, el paso de estilos y métodos de producción presentes en pueblos andinos a objetos suntuarios producidos para tiendas por departamento. Segundo, la conversión de personas sin formación académica en obreros capaces de responder a las demandas del mercado local e internacional. Si la sección “Investigación” y el apéndice registran objetos como cerámicas de Quinua, la sección "Experimentación" destaca los beneficios de combinar métodos de producción industriales y manuales. Esto da paso a los artículos de lujo de "Demostración; exhibición de ventas”. Dicha teleología modernista concluye en "Organización permanente de la producción comercial”, donde talleres, oficinas y planos arquitectónicos son complementados con retratos

18 "Carta de René d'Harnonourt a Truman Bailey", 6 de agosto de 1945. The Museum of Modern Art Archives, New York; Collection RdH; Section Folder II.30.

19 "Memorandum on a proposed plan for the study and promotion of the native arts and crafts of the two Americas", ca. 1941. The Museum of Modern Art Archives, NY; Collecion RdH; Section II.28.

20 The Museum of Modern Art Archives, NY; Collecion RdH; Section II.31.

21 Sobre los talleres de las Izcue, ver Majluf y Wuffarnden (1999, pp. 159-167).

22 "Carta de Truman Bailey a M.D. Carrell”, 10 de enero de 1943. The Museum of Modern Art Archives, New York; Collection RdH; Section Folder II.30. 


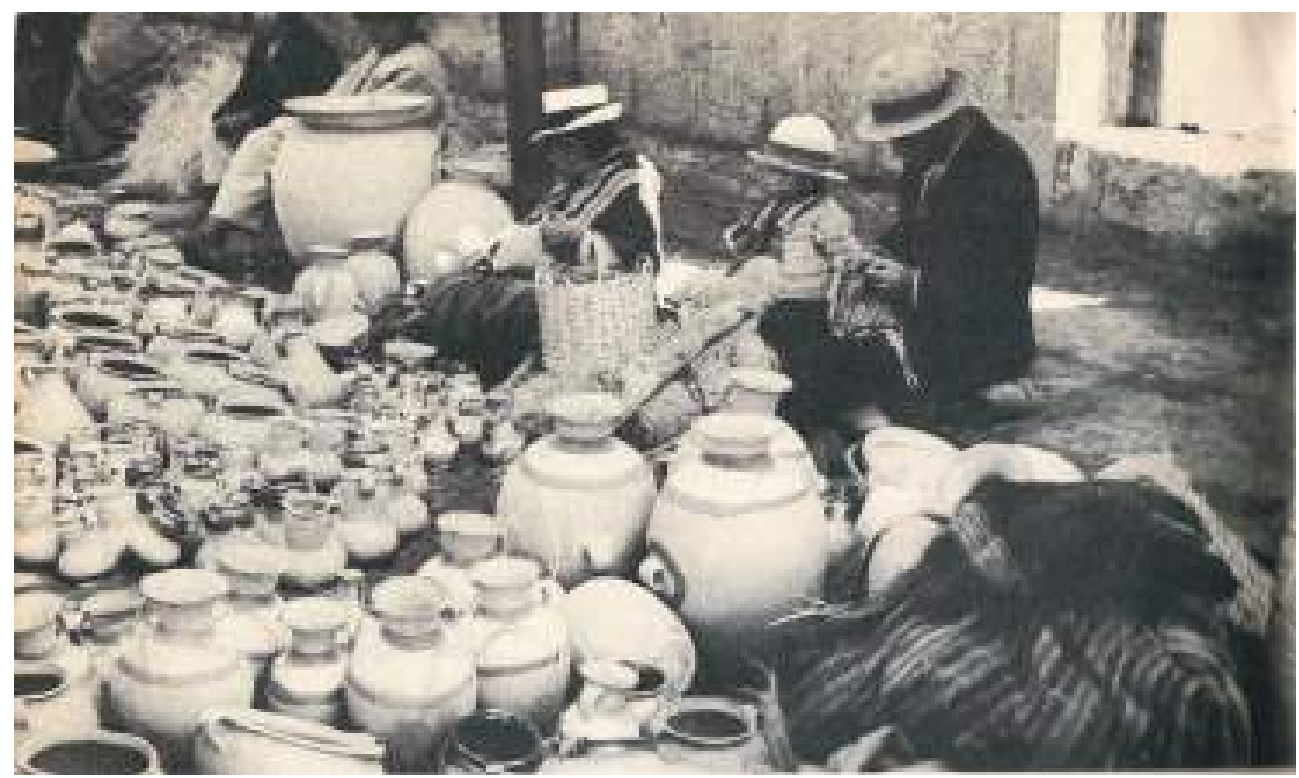

Fig. 3. Graciela “Grace” Vallejo. Mercado, ca. 1942. Fuente: Bailey y Vallejo (1946).

individuales de obreros y emprendedores. ${ }^{23}$

La sección "Investigación" introduce el Perú a una audiencia internacional. Sus páginas intercalan vistas apaisadas de montañas y lagos andinos; imágenes individualizadas de platería precolombina y textiles coloniales; delicados registros de plantas
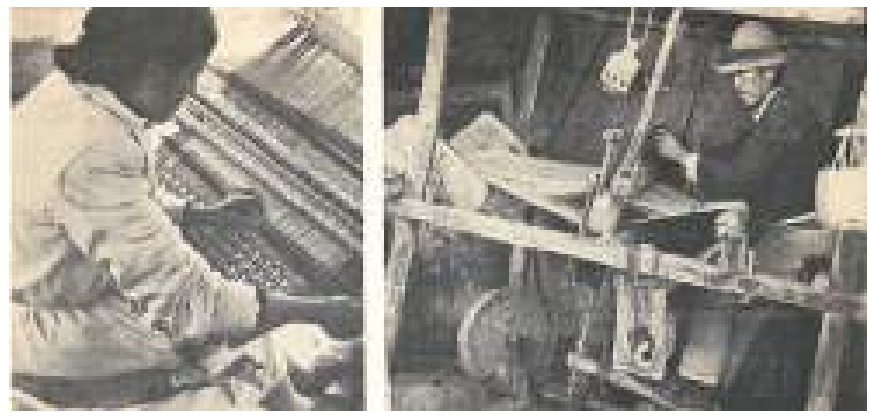

Fig. 4. Graciela "Grace" Vallejo. Mujer con telar de cintura| Hombre con telar de pedal, ca. 1942. Fuente: Bailey y Vallejo (1946). regionales e imágenes de carnavales y mercados del Altiplano. Por su estilo -entre la revista turística y el reporte político-, el catálogo hace eco de documentales como Lima (1943), producido por el cineasta estadounidense Julien Bryan para la Coordinadora de Asuntos Inter-Americanos. ${ }^{24}$ Dentro de este collage es posible notar, además, un discurso recurrente: los métodos de producción indígenas "puros" se están perdiendo. La sección inicia con una fotografía horizontal de un mercado cuzqueño no especificado, donde se pone en primer plano las ollas de barro ofertadas por lo que pareciera ser una familia nuclear ${ }^{25}$ (Fig. 3). En contraste, la página aledaña acusa la "invasión" de productos de plástico a través de tomas espontáneas y adustas de otros puestos en el mismo mercado.

23 Para un detallado reporte de las capacitaciones proyectados (pero solo parcialmente acometidos) por d'Harnoncourt, ver "Realm of Activities of a Proposed Departmanet of Indian Arts and Crafts of the Instituto Indigenista Inter-Americano". The Museum of Modern Art Archives, NY; Collecion RdH; Section II.28.

24 El video de este film está disponible en la plataforma Youtube, https://youtu.be/U1i_w2fc9Gg

25 Para Dr. Atl, los mercados rurales eran espacios de producción y circulación del arte que escapan de la alienación de la sociedad industrializada y capitalista (Montgomery, 2014, pp. 240-242). 


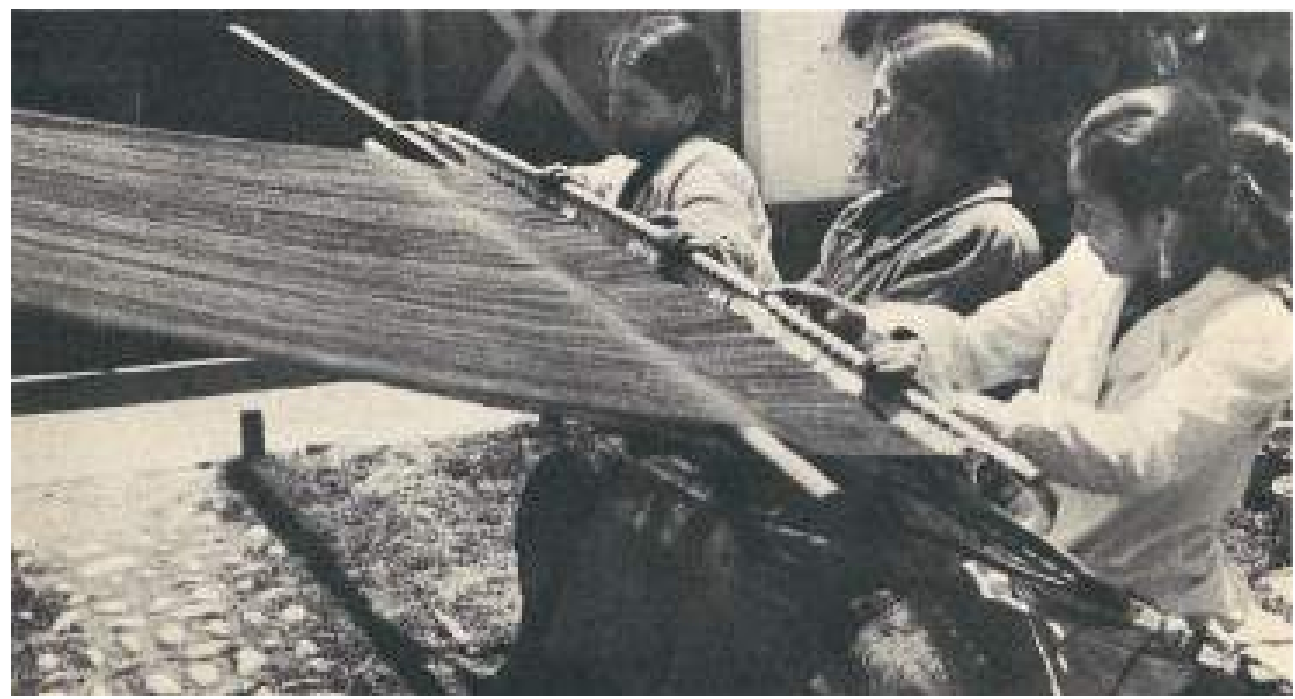

Fig. 5. Graciela “Grace” Vallejo. Trabajadoras, ca. 1945. Fuente: Bailey y Vallejo (1946).

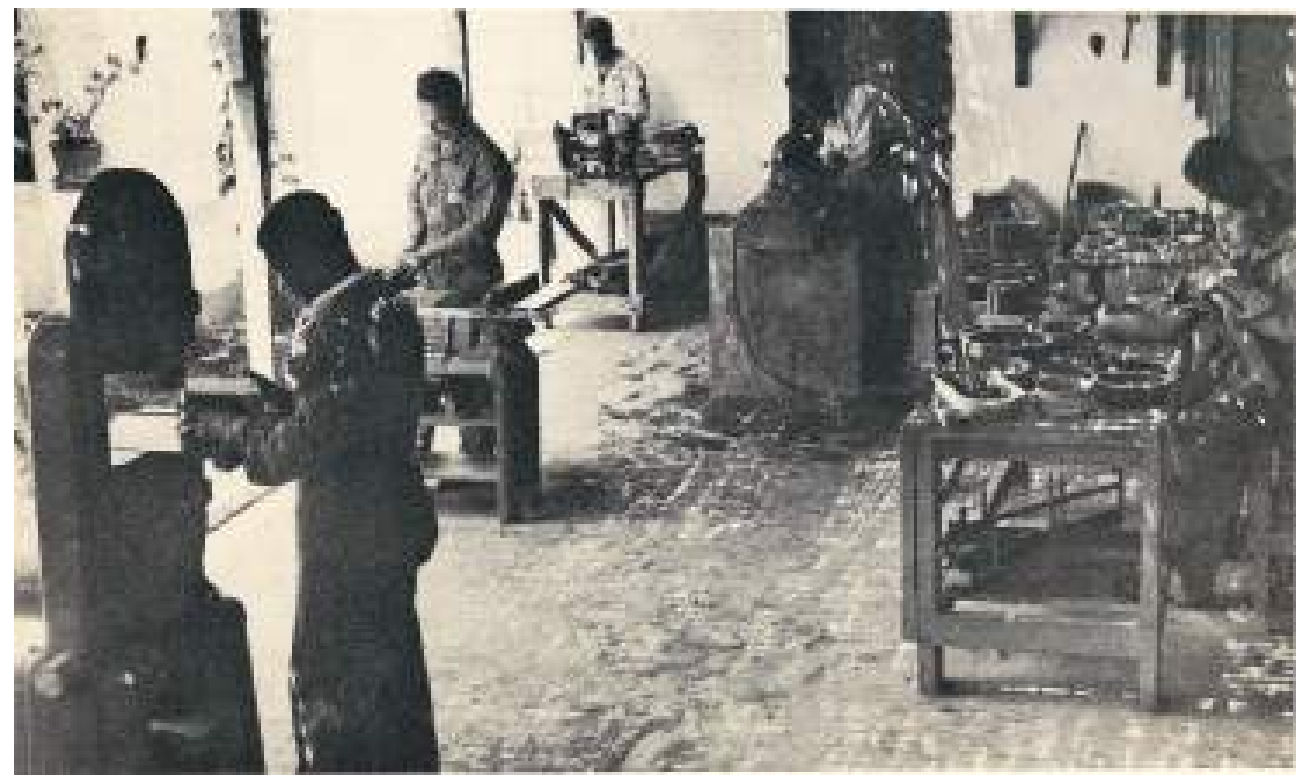

Fig. 6. Graciela “Grace” Vallejo. Trabajadores, ca. 1945. Fuente: Bailey y Vallejo (1946).

Como respuesta a esta "invasión", la sección "Experimentación" exhibe los beneficios de retomar prácticas manuales. Una de sus páginas yuxtapone una mujer utilizando un telar de cintura a un hombre operando un telar de pedal (Fig. 4). Este último, informa el texto, se ha popularizado, pese a ser más crudo y menos flexible que el de cintura, de origen precolombino. Contra esta situación, los modernos laboratorios (con muestrarios y microscopios) y espacios del taller de Bailey combinan artes manuales e industria. La sección "Experimentación" da cuenta, además, del aprendizaje logrado gracias al trabajo colaborativo. La chiclayana Margarita Romero y la ayacuchana Senobia García -se nos diceexperimentaron juntas en el mismo telar y aportaron distintas técnicas (una del norte y 
la otra del sur peruanos) a sus creaciones colectivas. (Fig. 5). Las fotografías exhiben, además, una clara división de género: las mujeres trabajando en los telares del jardín, y hombres como el platero Julio Lanao o el carpintero Luis Sánchez operando pesadas maquinarias (Fig. 6).

La sección "Demostración; exhibición de ventas" oferta los resultados de la experimentación previa: en la intersección de artes indígenas y tendencias del diseño internacional. Cucharas de metal y madera presentan diseños florales similares a los estudios de plantas de "Investigación"; ${ }^{26}$ a la vez, los mangos curvados de las cucharas no son disímiles a los de utensilios art nouveau que uno encontraría en tiendas por departamento. Una cigarrera de madera reproducida en el catálogo, por otro lado, exhibe un ave geométrica, tomada probablemente de textiles precolombinos, como los de la cultura Chancay (Fig. 7). Su geometría dialoga además con el art déco; algo que la artista Elena Izcue notó al emplear el mismo diseño para un cinturón producido en los treintas. Si "Investigación” y el apéndice reunían objetos de diseños recargados y "extravagantes" (flamboyant), como baúles coloniales o cruces ayacuchanas, "Demostración” se enfocó en depurados objetos. Así, las piezas del taller dieron forma al interés de d'Harnoncourt por modificar los objetos para mercados cosmopolitas. ${ }^{27}$ Incluso los toros de madera de Barsabas Cisneros (Fig. 1) ostentaron formas más simplificadas y una materialidad más adusta que los de las piezas comercializadas en Pucará.

En efecto, las piezas de The Manual Industries dialogaron con tendencias internacionales. Dichas tendencias no fueron determinadas solo por agentes estadounidenses o europeos, en tanto artistas latinoamericanos como Elena Izcue jugaron un rol importante en los mercados de artes decorativas de Nueva York y París. Por ejemplo, cuando el MoMA realizó su concurso internacional de diseño industrial en 1940, invitó a artistas latinoamericanos, a quienes, por lo demás, se les pidió destacar materiales y diseños "nativos"; un requerimiento que no se hizo a otras regiones. ${ }^{28}$ Entre las piezas ganadoras estuvieron los butaques del pintor y diseñador mexicano Xavier Gurrero, cuyas formas citaban las chaises longues diseñadas por los franceses Le Corbusier y Charlotte Perriand en los veintes, pero para cuya

26 Estos objetos son reproducidos en Davis Benavides (2014, pp. 10-25). Es todavía posible encontrar objetos similares en plataformas de venta virtual como ebay.com.

27 “Outline of a Proposed Study Program of Manual Industries". The Museum of Modern Art Archives, NY; Collecion RdH; Series Folder II.29.

28 Sobre los ganadores del concurso ver Noyes (1941, pp. 39-41). Perú participó, pero no he encontrado información sobre este envío. Sobre la exposición de los ganadores de este concurso, ver las imágenes y documentos en la web del MoMA, https://www.moma.org/calendar/exhibitions/1803 


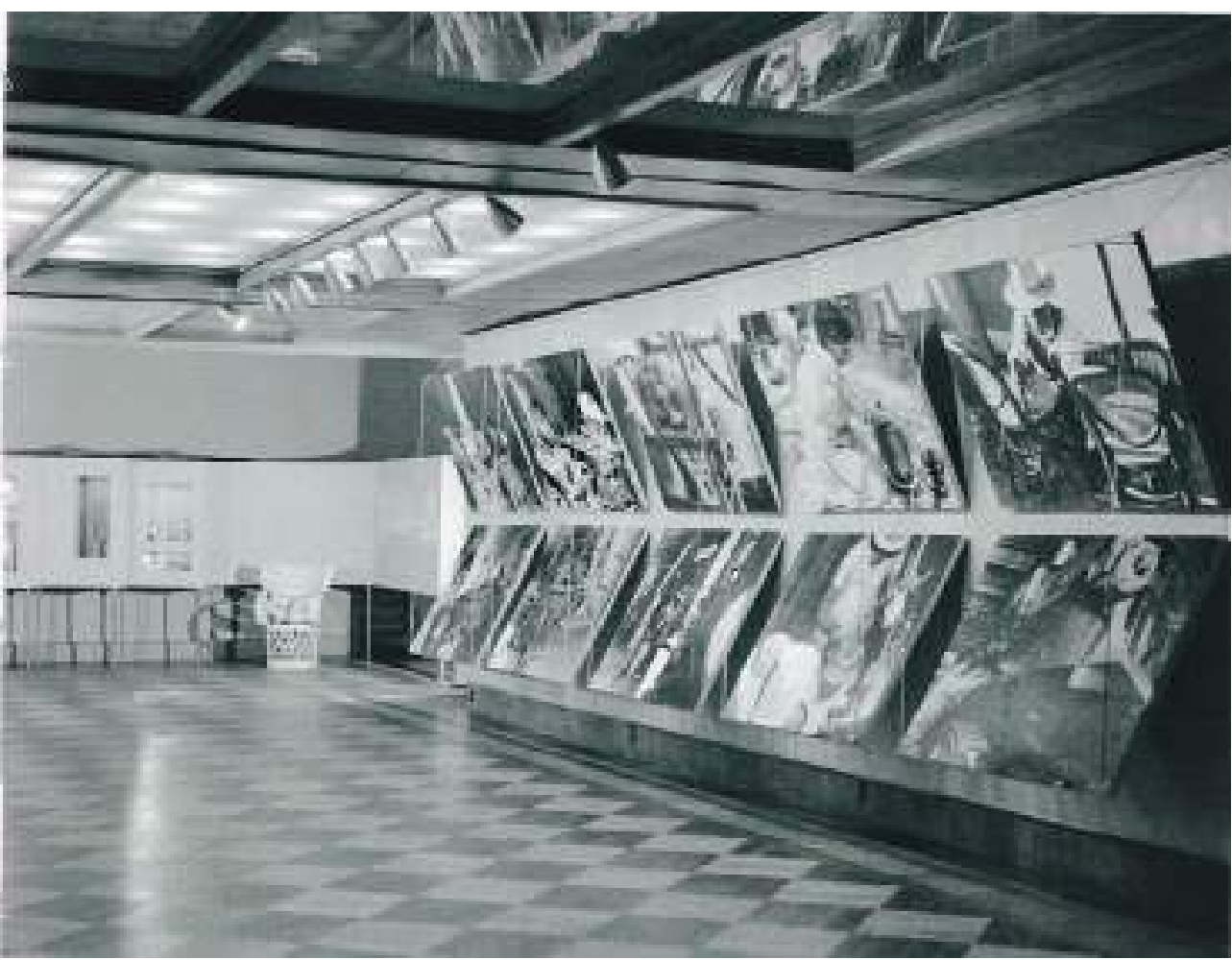

Fig. 9. Vista de El arte en la vida diaria: exposición de objetos de buen diseño hechos en México, 1952. Fuente: Porset (1952).

elaboración emplearon fibras de agave y paja mexicana. ${ }^{29}$ El taller de Bailey produjo piezas similares, por ejemplo, canastas e individuales cuyos ritmos concéntricos enfatizaban la materialidad y textura de la paja (Fig. 8). Estas piezas en fibra natural hicieron eco de los individuales que las hermanas Izcue desarrollaron con tejedoras en los mismos años, así como de canastas producidas desde los treintas en México por el ya mencionado Xavier Guerrero y su esposa, la aclamada diseñadora cubano-mexicana Clara Porset (Mallet, 2006).

Como Izcue, también Porset tuvo un lugar importante en la escena del diseño internacional desde los veintes. Un punto alto de su carrera fue la exhibición de 1952, Arte en la vida diaria, en el Instituto Nacional de Bellas Artes (Porset, 1952). Dicha exhibición afirmó el valor estético de textiles y cerámicas de origen indígena en un museo oficial, al incluirlas junto a piezas modernistas e industriales. También poco común fue la inclusión de fotografías de productores rurales y urbanos en las salas del museo (Fig. 9). Cabe indicar que la artista de origen cubano fue de filiación socialista, y su labor estuvo enmarcada por el ideario posrevolucionario mexicano (Sheppard, 2018). D’Harnoncourt también incluyó fotografías de artistas indígenas en la ya mencionada exhibición Indian Art in the United States (1941). En su caso, como ha notado Harper Montgomery (2014), dicha inclusión no sirvió para celebrar el trabajo comunitario -como en los proyectos de Dr. Atl o Porset-, sino que servía para darle estatus a mercancías con el fin de comercializarlas. En ese sentido, la inauguración de la exhibición Indian Art fue recordada por incluir a los artistas Navajo Charlie Turquoise y Diney Chilli pintando en la arena que fue instalada en sala (como si se tratase de un ritual)

29 Sobre la notable obra de diseño de muebles de Perriand, a menudo eclipsada por su vinculación al estudio de Le Corbusier, ver McLeod (2003). 


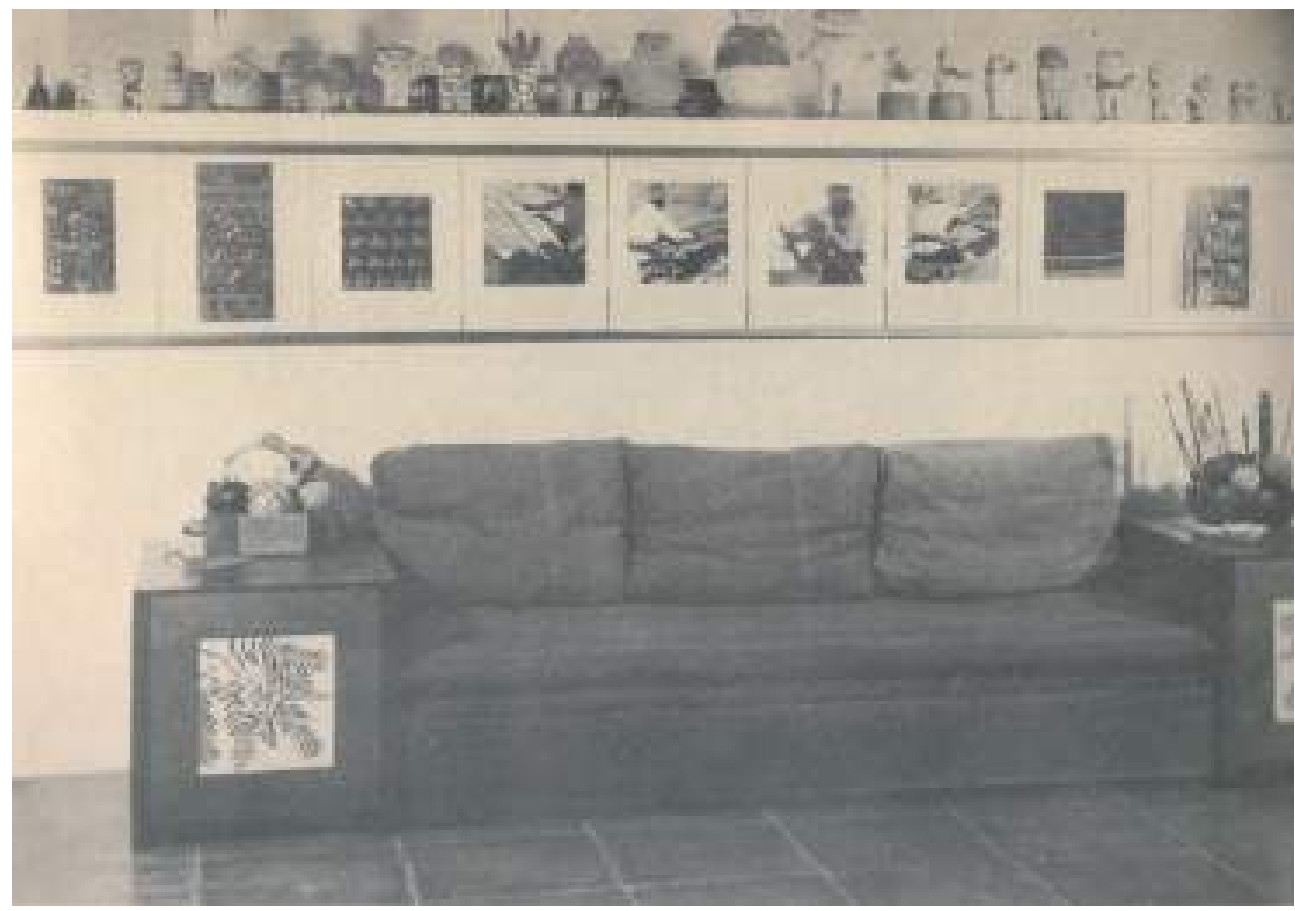

Fig. 10. Graciela “Grace” Vallejo. Sala de exhibición y venta, ca. 1945. Fuente: Bailey y Vallejo (1946).

para una fascinada audiencia (Schuchardt, 2015). ${ }^{30}$ Bailey y Vallejo debieron haber estado al tanto de estas tendencias curatoriales cuando decidieron incluir fotografías de sus trabajadores en sus salas de ventas en el taller de Miraflores (Fig. 10).

En última instancia, sin embargo, el taller no buscó operar como un museo o exhibición de tradiciones indígenas "puras". Apuntó desde el inicio a entrenar "maestros artesanos" capaces de insertarse en mercados urbanos. Esta visión estuvo limitada por la pérdida de apoyo privado estadounidense, y luego, por la dificultades para asegurar apoyo permanente de una entidad pública peruana. Un memorándum de abril de 1946 indica la creación del Instituto para el Fomento de las Artes Manuales, una entidad del Ministerio de Fomento dirigida por Bailey. Luego, en una carta de diciembre de Bailey a d'Harnoncourt, es posible encontrar el sello de instituto, cuyo logo fue el ave Chancay que se usó en cigarreras del taller. ${ }^{31}$ El mismo documento de diciembre, sin embargo, describe las dificultades para asegurar una deseada expansión (en más escuelas-talleres) y la sostenibilidad del proyecto. Según Bailey, el Estado demandaba más apoyo económico por parte de la Comisión Interamericana. Las cartas de los siguientes años sugieren además una tensa relación con la Administración del militar Manuel A. Odría (1948-1956), durante la cual los talleres de las Izcue también detuvieron sus funciones. La referencia más tardía a la existencia del taller es de 1951. Dicha nota mostró al taller no dentro de una estructura estatal, sino como un espacio privado de Bailey donde laboraban artistas como Basarbas Cisneros (Windsor, 1951).

30 Estas fotografías han sido reproducidas a menudo en la historiografía sobre el MoMA y se encuentran en: https://www.moma.org/calendar/exhibitions/2998?

31 "Ministerio de Fomento y Obras Públicas: Memorándum”, Lima, 29 de abril de 1946; "Instituto para el Fomento de las Artes Manuales: Carta der Truman Bailey a René d’Harnoncourt, 13 de diciembre de 1946. The Museum of Modern Art Archives, NY; Collecion RdH; Section Folder II.31. 
El cáustico artículo de Robert Ruark (1948) -mencionado al inicio de mi ensayo- no solo destacaba la aparente contradicción de que un "yanqui" enseñe a los peruanos "un curso de actualización de 3000 años sobre lo que sus ancestros hicieron" (a 3000-year-old refresher on how the ancestores did it). El artículo era en última instancia una denuncia. El taller proponía una dinámica laboral de mano de obra barata: artistas de clase trabajadora en un país del llamado Tercer Mundo produciendo bienes de lujo para tiendas por departamento en Nueva York. Tal situación, sugería Ruark, era habilitada por desigualdades entre países, pero también por una percepción paternalista hacia el arte y las personas de Perú. Esta percepción resultaba claramente falsa para cualquier peruano, afirmaba Ruark. El artículo empezaba con la irónica frase: "Nosotros los peruanos nativos nunca dejamos de asombrarnos del ingenio de los gringos" (Us native Peruvians never cease to marvel at the ingenuity of the Gringo).

La crítica de Ruark, si bien acertada en su afirmación de desigualdades estructurales entre países y productores, tenía por lo menos dos imprecisiones. Es cierto que d'Harnoncourt y Bailey hicieron arreglos para vender las piezas del taller en tiendas por departamento, como Lord \& Taylor y en el MoMA; y los archivos del MoMA incluyen una nota sobre una exhibición y venta de dichos objetos en una tienda la Quinta Avenida de Nueva York. ${ }^{32}$ Cabe notar, sin embargo, que en el documento fundacional del proyecto d'Harnoncourt destacó la importancia de que este se consolide en una agencia latinoamericana o "panamericana", por ejemplo, en el Instituto Indigenista Interamericano, creado en 1940 durante el Primer Congreso Indigenista Interamericano, en Pátzcuaro, Michoacán. ${ }^{33}$ En realidad, las cartas de d'Harnoncourt dan cuenta de su constante preocupación porque se consolide dentro del Ministerio de Fomento y Producción peruano. Como he descrito, este arreglo se deterioró durante la gestión de Odría.

Una segunda imprecisión en el artículo de Ruark se vinculaba a las percepciones de los propios peruanos sobre artes y personas indígenas; menos distantes a las de un "gringo" de lo que Ruark sospechaba. Como lo ha notado Paulo Drinot (2011), los distintos gobiernos de la primera mitad del siglo XX desarrollaron marcos legales diferenciados para obreros urbanos y campesinos rurales, en buena cuenta debido a que mantuvieron la percepción de que los campesinos eran indígenas y, por ende, "atrasados", y los obreros, mestizos y modernos. La industria moderna, así, podría "desindianizar" al Perú. Historiadores como Carlos Contreras (2016) han sugerido que esta distinción no se basó solo en percepciones racializadas, en tanto los dos tipos de trabajadores en efecto habitaron diferentes geografías y centros laborales. Sea como fuere, la masiva migración desde ciudades y pueblos andinos hacia Lima en la década de 1940 puso en contacto a dos grupos que desde la primera mitad del siglo XX habían sido percibidos como distintos por influyentes intelectuales y políticos, como José Carlos Mariátegui o Víctor Raúl Haya de la Torre (Drinot, 2011). ${ }^{34}$ Para Haya, en todo caso, la industria moderna podría crear puentes entre ambos grupos. En un manifiesto de 1932, por ejemplo, este promovió la solidaridad entre "artesanos" y obreros

32 "Carta de Truman Bailey a René d'Harnoncourt”. Papers, II.30. The Museum of Modern Art Archives, New York. See Letter from Truman Baily to M. D. Carrel, February 17, 1944. Sobre la exhibición, ver la nota de prensa "Peruvian Crafts Shown: Accessories for the Home and Street Wear are Included", s.f. The Museum of Modern Art Archives, NY; Collecion RdH; Section Folder II.31.

33 "Memorandum on a proposed plan for the study and promotion of the native arts and crafts of the two Americas", ca. 1941. The Museum of Modern Art Archives, NY; Collecion RdH; Section Folder II.28. Sobre el Instituto Indigenista Interamericano, ver Giraido 2011.

34 El censo de 1940 mostró que pese a que la mayoría de la población (62\%) se dedicaba aún a actividades rurales, la población de las ciudades la que había crecido más rápido que la del campo (Contreras y Cueto 286). 
pues compartían la condición de "clases productoras". 35

En la línea de las palabras de Haya, el taller de Bailey enlazó discursos indigenistas y desarrollistas en la figura del "maestro artesano". Si bien el ideario del taller afirmó una retórica de preservación de tradiciones indígenas, sus organizadores aplicaron métodos del capitalismo industrial dentro del contexto urbano limeño. Cabe notar, por lo demás, que d'Harnoncourt tuvo en alta estima a Haya, y sus archivos conservan una nota periodística que destacaba la idea de un "frente único" de artesanos e intelectuales. ${ }^{36}$

Considero también que los propios productores (la gran mayoría, migrantes andinos y de ascen-

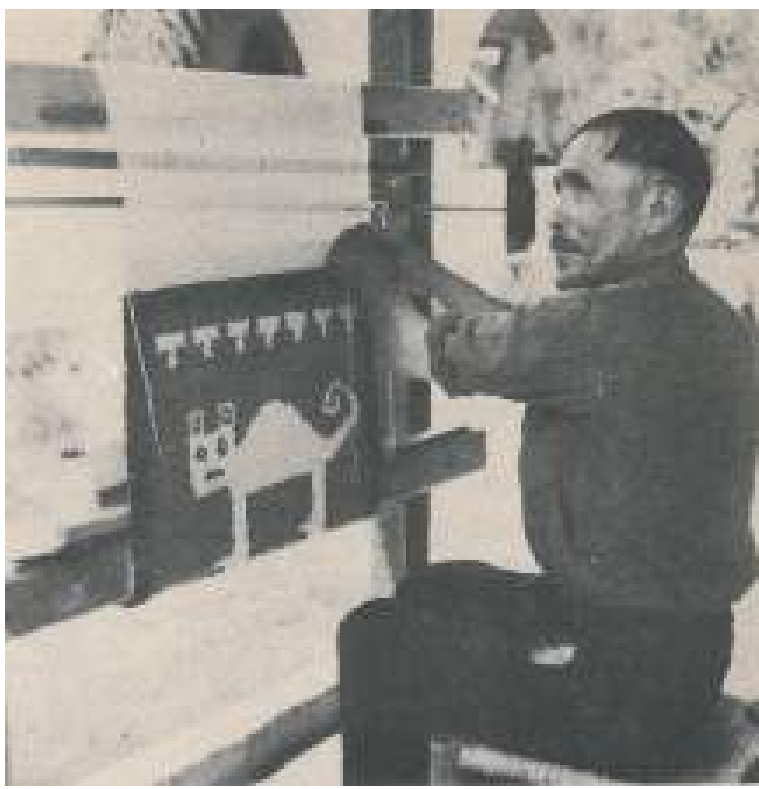

Fig. 11. Graciela "Grace” Vallejo. Gregorio Vilca, ca. 1945. Fuente: Bailey y Vallejo (1946).

dencia indígena) supieron reconocer y capitalizar los discursos indigenistas y desarrollistas del taller. Si hemos de creer a lo escrito en el catálogo, fue ahí donde Gregorio Vilca -de “origen aimara”- perfeccionó técnicas textiles que empleó luego cuando volvió a su natal Puno (Fig. 11). Además, en los años siguientes, el platero y joyero Oscar San Miguel abrió un taller propio en el distrito de clase trabajadora de La Victoria. San Miguel, como el tallador Barsabas Cisneros, consolidaron una clientela cautiva por décadas. ${ }^{37}$

Los alcances del taller deben ser aquilatados en el marco de un contexto social que no ofrecía muchas opciones para personas de clase trabajadora percibidas como no-blancas (Borea, 2017). No sería hasta la década siguiente que Isabel Benavides y John Davies abrieron el Art Center en Lima (Munive, 2015); o que la Escuela Nacional de Bellas Artes de dicha ciudad proyectó una Sección de Artesanías Artísticas, que sería el eje de escuelas regionales en ciudades como Cuzco y Puno (Cruz, 2018). Pese a este contexto poco favorable, Oscar San Miguel no solo mantuvo su taller hasta la década de 1980, sino que además ganó un premio del Ministerio de Turismo en 1998. Y en su estela, su hija Rocío San Miguel sostiene hasta hoy un negocio de platería. ${ }^{38}$ El taller de Bailey constituyó entonces un espacio donde productores consiguieron insertarse en los discursos, estilos y redes del arte y el diseño modernistas. Redes que ciertamente privilegiaron a instituciones como el MoMA y a agentes como d'Harnoncourt, pero que también permitieron el desarrollo de carreras individuales de artistas locales específicos.

35 Tomo esta cita de Davis Benavides (2014), quien cita a su vez Víctor Raúl Haya de la Torre, "Aprismo no es comunismo. No todo marxismo es comunismo" (febrero de 1932).

36 "El gran forjador del frente único de trabajadores manuales e intelectuales", s.f. The Museum of Modern Art Archives, NY; Collecion RdH; Section II.31.

37 El coleccionista y curador John Alfredo Davis Benavides (cuyos padres, Isabel Benavides y John Davis, conocieron a Bailey y Vallejo) contrató los servicios de ambos artistas hasta la década de 1990. Comunicación personal con John Alfredo Davis Benavides, 1 y 3 de setiembre de 2020.

38 Sobre Platería San Miguel, ver http://www.plateriasanmiguel.com/ 
Bailey, T. y Vallejo de Escardó, G. (1946). The Manual Industries of Peru: Report on a Project of the Inter-American Development Commission. Nueva York: Museum of Modern Art.

Borea, G. (2017). "Arte popular y la imposibilidad de sujetos contemporáneos; o la estructura del pensamiento moderno y la racialización del arte”. En G. Borea (ed.), Arte y antropología: estudios, encuentros y nuevos horizontes, pp. 97-119. Lima: Fondo Editorial PUCP.

Contreras, C. y Cueto, M. (2013). Historia del Perú contemporáneo. Desde las luchas por la Independencia hasta el presente. 5. ${ }^{\text {a }}$ edición. Lima: Instituto de Estudios Peruanos.

Contreras, C. (2016). "La seducción de la clase obrera: trabajadores, raza y la formación del Estado peruano". En: Economía, XXXIX, n 77, pp. 267-269. Lima: Instituto de Estudios Peruanos y Ministerio de Cultura.

Cordero, K. (2010). "La invención del "arte popular": una estrategia para la construcción del arte mexicano moderno". En A. Garduño (ed.), Facturas y manufacturas de la identidad: las artes populares en la modernidad mexicana, pp. 73-95. D.F. México: Museo de Arte Moderno.

Cruz, P. (ed.). (2018). Escuela Nacional Superior Autónoma de Bellas Artes del Perú. Centenario 1918-2018. Lima: Escuela Nacional Superior Autónoma de Bellas Artes del Perú.

Davis, J. (ed.) (2014). ¿Arte popular: tradiciones sin tiempo? Lima: Instituto de Investigaciones Museológicas y Artísticas-ICPNA.

De la Cadena, M. (2000). Indigenous mestizos: The Politics of Race and Culture in Cuzco, Peru 1919-1930. Durham: Duke University Press.

Del Real, P. (2012). Building a Continent: The Idea of Latin American Architecture in the Early Postwar. Tesis doctoral, Nueva York: Columbia University.

Drinot, P. (2011). The Allure of Labor: Workers, Race, and the Making of the Peruvian State. Durham: Duke University Press.

Elligott, M. (2018). René d'Harnoncourt and the Art of Installation. Nueva York: The Museum of Modern Art.
Germaná, G. y Borea, G. (2008). "Discusiones teóricas sobre el arte en la diversidad". En: Grandes maestros del arte peruano, Urbano, Mérida, Rojas y Sánchez, pp. 12-21. Lima: TGP.

Giraudo, L. (2011). "Un campo indigenista transnacional y "casi profesional": la apertura en Pátzcuaro (1940) de un espacio por y para los indigenistas". En: L. Giraudo (ed.), La ambivalente historia del indigenismo: campo interamericano y trayectorias nacionales 1940-1970, pp. 21-98. Lima: Instituto de Estudios Peruanos.

Greet, M. (2019). "Looking South: Lincoln Kirstein and Latin American Art”. En S. Friedman y J. Hauptman (eds.), Lincoln Kirstein's Modern, pp. 144-154. Nueva York: Museum of Modern Art.

Herrera, O. (2017). American Intervention and Modern Art in South America. Gainesville: University of Florida.

Kogod, L. (2015). “The Display Window as Educator: The German Werkbund and Cultural Economy". En P. Deamer (ed.). Architecture and Capitalism. NewYork: Routledge.

López, R. (2010). Crafting Mexico: Intellectuals, Artisans, and the State after the Revolution. Durham: Duke University Press.

Loschiavo dos Santos, M.C. (1995). Móvel moderno do Brasil. São Paulo: Senac São Paulo.

Majluf, N. y Wuffarden, L. E. (1999). Elena Izcue: el arte precolombino en la vida moderna. Lima: Museo de Arte de Lima.

Majluf, N. y Wuffarden, L. E. (2011). José Sabogal. Lima: Museo de Arte de Lima.

Mallet, A. E. (2006) El diseño de Clara Porset inventando un México moderno. Madrid: Turner.

McLeod, M. (2003). "New Designs for Living: Domestic Equipment of Charlotte Perriand, Le Corbusier, and Pierre Jeanneret, 1928-29”. En M. McLeod (ed.), Charlotte Perriand: An Art of Living, pp. 36-67. Nueva York: H. N. Abrams.

Montgomery, H. (2014). "From Aesthetics to Work: Displaying Indian Labor as Modernist Form in Mexico City and Nueva York". En: Modernism/Modernity 21(1), enero, pp. 231-251. Baltimore: Johns Hopkins University Press DOI: $10.1353 / \bmod .2014 .0025$ 
Munive, M. (ed.) (2015). Isabel Benavides y John Davis: impulsores de las artes. Lima: ICPNA.

Noyes, E. (1941). Organic Design in Home Furnishings. Nueva York: Museum of Modern Art.

Rangel, G. (ed.) (2015). Moderno: Design for Living in Brazil, Mexico, and Venezuela, 19401978. Nueva York: Americas Society.

Rivas, J. (2015). “Cannibal Homes: Additive Modernity and Design by Absorption in Brazil, Mexico and Venezuela". En G. Rangel (ed.), Moderno: Design for Living in Brazil, Mexico, and Venezuela, 1940-1978, pp. 30-45. Nueva York: Americas Society.

Ruark, R. (1948). "Smart Yank shows Peruvians it pays to be Primitive". 10 de junio En: The Washington Daily News.

Sabogal, J. (1949). El toro en las artes populares. Lima: Ministerio de Educación Pública, Museo de la Cultura Peruana.

Sheppard, R. (2018). "El exilio y la política transnacional en el diseño de Clara Porset". En: R. Sheppard et al. (eds.). Horizontes del exilio. Nuevas aproximaciones a la experiencia de los exilios entre Europa y América Latina durante el siglo XX, pp. 91-123. Madrid: Iberoamericana Vervuert.

Schuchardt, E. (2015). Native American Chic: The Marketing of Native Americans In NewYork
Between the World Wars. 2015. Tesis doctoral, Nueva York: The City University of New York.

Spahni, J. C. (1966). La cerámica popular del Perú. Lima: Peruano Suiza, S.A.

Stastny, F. (1981). Las artes populares del Perú. Lima: Edubanco.

Villegas, L. F. (2006). "El Instituto de Arte Peruano (1931-1973): José Sabogal y el mestizaje en arte". En: Illapa 3, diciembre, pp. 21-44. Lima: Instituto de Investigaciones Museológicas y Artísticas, Universidad Ricardo Palma.

Windsor, J. R. (ed.) (1951). "Reviving the Ancient Andean Arts". En: Popular Mechanics 96, n. 4 (octubre): pp.140-141. Santa Mónica: H. H. Windsor, J. R.

Yllia, M. E. y Carpio, K. (2006). "Alicia y Celia Bustamante, la Peña Pancho Fierro y el Arte Popular". En: Illapa 3, diciembre, pp. 45-60. Lima: Instituto de Investigaciones Museológicas y Artísticas, Universidad Ricardo Palma.

Recibido el 28 de agosto de 2020 Aprobado el 15 de octubre de 2020 